\title{
DISPOSITIVOS DE REGULAÇÃO DA DOCÊNCIA NAS POLÍTICAS DE CURRÍCULO
}

\author{
Rosanne Evangelista Dias \\ Universidade do Estado do Rio de Janeiro - UERJ, Brasil \\ Márcia Betânia de Oliveira
}

Universidade do Estado do Rio Grande do Norte - UERN, Brasil

As regulações em terreno instável da formação e da atuação docente nos permitem afirmar que não há espaço sem regulação. Mas se não há espaço não regulado, também não há regulação total ou plena. Ao abordar dispositivos de regulação a partir de uma abordagem discursiva, buscamos problematizar efeitos perversos da regulação quando cria constrangimentos para a atuação de atores sociais, mas que também permite modos de reagir a esses impedimentos. Desse modo, compreendemos que o efeito mais perverso da regulação é quando permitimos que os constrangimentos que ela produz despotencialize criações de espaços para a produção de outros sentidos. Quando deixamos à deriva possíveis traduções, recontextualizações e deslocamentos. Por mais implacável que os dispositivos de regulação possam operar, defendemos que há espaço para produzir traduções, para deslocar os sentidos em outras significações.

Compreendemos as regulações como tentativas de restringir o processo de diferir os currículos, as formações com padronização, também como centralização, controle, responsabilização, censura, etc.. Contudo, concordando com Lopes e Macedo (2011) nenhum controle torna possível cessar os diferentes sentidos, “como narrativas que buscam evitar que se pense diferente” (p.215).

Assim, vimos acompanhando nos discursos produzidos e difundidos por organismos internacionais, normativas de diferentes países e entidades representativas do movimento social e do terceiro setor a nos desafiar a refletir, criticamente, sobre a centralidade atribuída aos docentes no seu trabalho na escola básica e no ensino superior, impactando as políticas para a educação.

Textos políticos em diferentes escalas assumem o protagonismo docente como crucial para a qualidade da educação e, de modo ambivalente, pretendem desenhar um suposto perfil para os professores por um lado enquanto autores/protagonistas, por outro, enquanto responsáveis pelo resultado do desempenho dos seus alunos. 
Observamos em textos políticos da Organização dos Estados Ibero-americanos - OEI, como o Miradas sobre la Educación en Ibero-América: Desarrollo profesional docente y mejora de la educación (2013) o retorno ao discurso em defesa de modelos de avaliação do desempenho de professores que intentam a processos de formação que possam responder a uma estandardização de "marcos claros y explícitos de qué se espera de un "buen alumno" y un "buen docente” y, en consecuencia, de una claridad sobre 'qué y cómo aprender' y 'qué y cómo enseñar”’ (OEI, 2013, p.159). Uma obsessão pela eficiência, via currículo por competências como recurso para modelar o trabalho docente a partir de processos de avaliação de desempenhos, previamente definidos considerando os resultados como evidências na linguagem atual desses documentos.

No último texto político da OEI, intitulado Miradas sobre Educação na Ibero-América 2020: competências para o Século XXI na Ibero-América (OEI, 2020) são lançadas a base da avaliação por desempenho a ser monitorada pelos relatórios de organismos internacionais e dos Estados: as competências e o desenvolvimento de processos de criação de padrões de aprendizagem escolar e profissional. O referido texto argumenta, ainda, que "as competências estão vinculadas aos resultados da aprendizagem, com o objetivo de capacitar as pessoas a saberem responder de forma eficaz aos desafios escolares e sociais ou, mais especificamente, aos padrões de conteúdo” (OEI, 2020, p.72).

Biesta (2021) destaca, em ensaio, como a obsessão com a eficácia tem tomado centralidade entre "pesquisadores educacionais e os criadores de políticas, esquecendo-se que educação eficaz nunca é automaticamente ou necessariamente boa educação” (BIESTA, 2016 apud BIESTA, 2021, p.2). O autor problematiza o surgimento do que vai denominar como "indústria global de mensuração da educação" (BIESTA, 2021, p.2) que disputa a qualidade da educação pressionando por resultados que possam ser demonstrados por desempenhos afetando a docência desde a formação até a atuação.

Currículo e processos de avaliação do desempenho têm estado presentes no Brasil e em outros países, em propostas e normativas orientadoras de políticas de currículo para a docência, como tentativas de controle da profissão. Operando com a organização curricular por competências e a avaliação do desempenho docente delineiam-se, em um contexto conservador, modos de significar o trabalho docente voltados à instrumentalização e padronização de percursos de formação inicial e continuada para fins de mensuração dos processos avaliativos. Tais processos engendram dispositivos de regulação desses profissionais que merecem nosso aprofundamento e problematização.

Contudo, as contingências, especialmente as vividas na pandemia da Covid-19 vividas desde 2020 no Brasil, nos interpelam a desconstruir discursos das políticas de currículo e sobre a docência, como nos convidam Laclau e Mouffe (2015). Nos desafiam ao imprevisível nos instando a produzir outros modos de pensar e produzir currículos e docências sem a pretensão de apresentar soluções e posições definitivas, mas caminhos possíveis, contrariando as perspectivas que buscam projetar comportamentos, resultados, eficácia.

A partir dessa temática propomos a discussão das significações que vêm sendo articuladas nas políticas de currículo em disputa e seus efeitos na atuação dos professores na escola básica e no ensino superior. Questionamos: que implicações podem reverberar nas 
subjetividades docentes a partir das políticas com foco em comportamentos observados, mensurados, demonstrados, associados meramente a resultados de desempenho? Que dispositivos de regulação atravessam essas políticas e como os movimentos da educação vêm respondendo em nome de proposições mais arrojadas em outros processos de articulação política?

Ao lançarmos a proposta para o Dossiê da Associação Brasileira de Currículo (ABdC) intitulado Dispositivos de regulação da docência nas políticas de currículo, nossa expectativa era a de mobilizar entre os pesquisadores o debate sobre as políticas de currículo voltadas à docência, abordando, com centralidade, mecanismos que vêm propagando modos de controlar as subjetividades, o trabalho, a política no Brasil. A resposta ao convite por parte dos autores, ao nos enviarem os artigos nos colocou diante de uma demanda importante no campo do currículo trazendo discussões que, por diversas escolhas, apontavam abordagens teóricas e metodológicas em diálogo com autores nacionais e estrangeiros com espectro amplo, das perspectivas pós-estruturais às estruturais.

No processo de organização do Dossiê registramos a submissão de 32 artigos, alguns deles sem aderência à proposta apresentada e 28 aprovados (incluindo os convidados estrangeiros) com a participação ativa de muitos pareceristas que foram acionados no processo de avaliação, a quem agradecemos pelo empenho no relevante trabalho. Nessa perspectiva, reiteramos a existência de uma ampla rede que se fortalece a cada dia, que vai desde a autoria dos trabalhos então submetidos, até os pareceristas envolvidos na lisura do processo de avaliação desses trabalhos. Como afirmam Lopes e Oliveira (2017, p.15), "Redes de políticas, redes de conhecimento, redes de pesquisa [...] se constituem por uma lógica que dispara resultados imprevistos, em uma estrutura descentrada. São decorrentes de articulações discursivas que constituem um contexto [...]”. A ABdC tem se apresentado nos últimos anos como expressivo espaço de produção e circulação de pesquisas em diálogo com diferentes temáticas, possibilitando a ampliação dessas redes no campo do currículo. Nesse sentido, os textos que compõem este Dossiê, reservadas suas singularidades, ampliam o debate em torno de temas com foco em/nos Dispositivos de regulação da docência nas políticas de currículo

Abrimos o dossiê com o ensaio de Ángel Díaz-Barríga, intitulado Políticas curriculares y de evaluación en México, proyectos de los organismos internacionales y cambios en la práctica docente que analisa as implicações das políticas de currículo e de avaliação influenciadas pelos organismos internacionais nos últimos 40 anos no país sobre a prática docente. Identifica a emergência de grupos de cunho nacionalista e de esquerda no âmbito da política pública que buscam romper com algumas propostas estabelecidas no campo político sem, contudo, avançar em proposições educacionais que se afastem dos modelos estabelecidos.

Roberto Sidney de Macedo com seu artigo Políticas de currículo, formação e fetiche: a propósito de príncipes, simplificações e idolatrias trata de como políticas de currículo e formação utilizam-se de concepções e referências, apresentando-as como compreensões e orientações deônticas, configuradas, não raro, como fetiches. Macedo compreende os processos de fetichização a partir de espaçostempos nos quais a produção de fetiches se 
realiza de forma culturalmente plural e generativa e nos provoca, diante dos contextos das políticas curriculares do presente, a questionarmos a emergência do currículo como produção cultural pensadapraticada de forma realçada como um fetiche.

$\mathrm{O}$ artigo A docência na educação infantil da rede pública municipal do Rio de Janeiro atravessada pelos materiais didáticos estruturados, de Cátia Cirlene Gomes Oliveira, relata a experiência dessa rede de ensino durante o período de suspensão de aulas presenciais devido à pandemia da COVID-19, ao reorientar a produção e uso dos cadernos pedagógicos - material didático destinado ao uso pelas crianças - com a necessidade de manter, principalmente, o vínculo entre as escolas, as famílias e os alunos da Educação Infantil. Nessa experiência, a autora defende como as interpretações para uma política e a sua finalidade podem ser alteradas pelas contingências, encontrando novas brechas e promovendo novas significações e novos usos para as políticas.

Em Narrativas docentes e criação curricular, desafios de tempos pandêmicos, Graça Regina Franco da Silva Reis, Marina Santos Nunes de Campos e Ilana Maria Martins abordam dispositivos de regulação que permeiam a docência e os currículos atravessados no/pelo contexto da pandemia de COVID-19, em que a escola se (re)desenha por necessidade de existir e resistir. A criação curricular cotidiana acontece de diversas outras formas que não aquelas pretendidas pelas políticas de currículo e formação atuais pelas mãos de milhares de professoras que teimam em produzir conhecimentos com seus estudantes, apesar da precariedade a que, por vezes, seu trabalho é submetido.

O texto Universidadeescola e a descolonização do currículo de formação de professores e professoras: complexidade, transdisciplinaridade e decolonialidade, de Eglê Betânia Portela Wanzeler, Marcos André Ferreira Estácio e Maria Quitéria Afonso Menezes, questiona em perspectiva decolonial, a partir de um projeto de formação realizado em escolas da Rede Pública da cidade de Manaus, como construir nos espaçostempos dos cotidianos escolares processos formativos continuados que sejam capazes de promover e/ou criar novos modos de fazer, pensar e sentir o currículo de formação inicial e continuada.

Dulce Mari Silva Voss, no artigo Espelhos quebrados: imagem de uma docência autoempreendedora, aborda, no contexto pandêmico, demandas em torno dos interesses de um mercado educacional em franca expansão a requererem da docência a aquisição de competências e habilidades no manuseio das ferramentas tecnológicas e digitais para dar conta de uma nova modalidade do trabalho pedagógico: o ensino remoto, nos ambientes privados dos domicílios. Diante das telas-espelho projeta-se uma performatividade narcisista agenciada pela qualidade empresarial e levada a efeito pela ordem biopolítica neoliberal que requer a responsabilização moral pelos resultados a serem alcançados, de modo a capturar a docência e neutralizar potências de criação de um devir-outro.

As representações sobre a prática pedagógica, em ações para a implementação e em discursos de convencimento sobre a relevância de políticas curriculares oficiais endereçados a docentes do ensino básico, são abordadas no artigo Vozes e mensagens nos materiais de apoio à implementação da BNCC, de Cláudia Valentina Assumpção Galian, Émerson de Pietri e Lúcia Helena Sasseron. A análise focaliza os textos produzidos e dirigidos aos 
professores pelo Ministério da Educação brasileiro para a divulgação da Base Nacional Comum Curricular, em um evento denominado de Dia " $D$ ” da Base.

O artigo Trazendo o contexto para o centro da análise sobre a atuação das políticas: um estudo acerca da Reforma do Ensino Médio e da BNCC em escolas do Ceará, de Brena Kécia Andrade de Oliveira e Meyre-Ester Barbosa de Oliveira destaca tais documentos como frutos de uma articulação hegemônica que tem o intuito de fixar sentidos sobre a educação e de normatizar os processos educativos, incluindo a atuação dos professores. Destaca que, apesar da institucionalização de novas formas de práticas e culturas organizacionais, que acentuam os mecanismos de regulação da docência, as políticas são interpretadas nas escolas de maneiras distintas, uma vez que as orientações e as padronizações globais somente se instituem mediante processos de negociação com demandas contextuais.

Rita de Cássia Prazeres Frangella, no artigo Ensinando por códigos: construindo uma docência padronizada, discute a padronização do ensino incitada pelo advento da BNCC e como seu desenho curricular se constitui dispositivo de regulação do trabalho docente. Focaliza os usos e significação dos códigos alfanuméricos que identificam e organizam as competências e habilidades descritas na BNCC. Defende o investimento na análise dessa intrincada articulação discursiva que envolve as significações acerca da educação, ensino e trabalho decente, bem como os afetos que participam desse processo.

Entre políticas de regulação e resistências coletivas: imagens-cinema agenciando linhas de vida aos movimentos curriculares, de Sandra Kretli da Silva, Ana Cláudia Santiago Zouain e Nathan Moretto Guzzo Fernandes, problematiza as políticas educacionais neoliberais como a BNCC e as Diretrizes Curriculares Nacionais para a Formação Inicial de Professores da Educação Básica (BNC-Formação inicial e continuada), argumentando a força das imagens cinematográficas em encontros formativos com professores de escolas municipais de Vitória/ES, na composição de processos de resistências ético-estético-políticos que afirmam a potência das infâncias.

No artigo Formação e trabalho docente: intencionalidades da BNC-Formação Continuada, Eliane Miranda Costa, Cleide Carvalho de Matos e Vivianne Nunes da Silva Caetano abordam a política pública de formação continuada de professores no Brasil focalizando a Resolução CNE/CP $n^{0}$ 1, de 27 de outubro de 2020, destacando implicações dessa Resolução e da BNC-Formação Continuada para o trabalho docente e para o processo formativo do aluno da educação básica.

O tornar-se professor(a) no currículo de ciências: tensionando as teses culturais da BNCC e da BNC-Formação, de Catarina de Cassia Moreira, Marcia Serra Ferreira e Beatriz Pereira, identifica como os textos BNC-Formação e BNCC participam da constituição de teses culturais sobre a subjetividade docente, com efeitos no ensino das disciplinas escolares em ciências. Destaca ser possível encontrar outras formas de fazer educação que questionam e subvertem a normatividade, por meio das quais sujeitos(as)-professores(as) encontrem brechas para desterritorializar os processos educativos.

Em $\mathbf{O}$ sujeito docente da diversidade e da diferença nas diretrizes curriculares de formação, Ann Letícia Aragão Guarany e Lívia de Rezende Cardoso discutem como estão 
dispostas discursividades acerca do sujeito docente para a diversidade e a diferença nas Diretrizes Curriculares para cursos de formação inicial homologadas em 2015 e 2019, seus desejos de governo e as subjetivações que pretendem.

Hugo Heleno Camilo Costa e Érika Virgílio Rodrigues da Cunha abordam Normatividade, desconstrução e justiça: para além do dever ser na Base Nacional Comum da formação de professores, em cujo texto focalizam a relação entre a Resolução 02/2019 e a BNCC para a educação básica para problematizar a busca por fundamentação curricular através da decisão pela normatividade como justificativa para a garantia de acesso ao direito à educação para determinado sujeito. Tencionam a proposta restritiva de currículo comum afirmando-a como antidemocrática e apartada da justiça, por pautar a subjetividade ao dever ser, por visar restringir a diferença ao comum e transparente.

A constituição da identidade docente entre a projeção do mercado e as lutas do comum, de Derlan Trombetta e Maria Beatriz Luce, examina como a formação de professores assumiu a centralidade nas reformas educacionais contemporâneas, analisando a forma como a racionalidade neoliberal se impôs nas políticas de formação de professores, sob os desígnios do gerencialismo e da performatividade como tecnologias políticas.

Bruna Senna Dias e Carmen Teresa Gabriel, por sua vez, ao questionarem A quem interessa a profissionalização docente?, em diálogo com as contribuições teóricas da abordagem discursiva pós-fundacional, problematizam desdobramentos dessa temática no processo de significação da docência na Resolução CNE/CP n 2/2019.

No texto Base Nacional Comum para Formação de Professores da Educação Básica: em foco os jogos políticos e a responsabilização docente, Débora Barreiros e Rosalva de Cássia Rita Drummond problematizam as noções relacionadas aos direitos de aprendizagem, espectro de justiça e a responsabilização docente, em detrimento dos sentidos mais amplos do Direito à Educação. Consideram que a proposta BNC-Professores reforça o poder regulatório e normativo do governo, resultando num movimento de perda de autonomia docente e de identidade profissional.

EDUCAÇÃO 2030: tendências, influências e ausências nas políticas de formação inicial de professores, é tema do texto das autoras Danielle Engel Cansian Cardoso, Romilda Teodora Ens e Thalita Vianna de Lima, as quais identificam a relação entre o proposto no documento "Educação 2030: Declaração de Incheon e Marco de Ação da Educação", publicado pela Unesco (2016) e a Resolução CNE/CP n. ${ }^{\circ}$ 2/2019, com ênfase em duas abordagens estratégicas contidas no documento da Unesco (2016): “focar na qualidade e na aprendizagem" e "promover a aprendizagem ao longo da vida".

Samuel Molina Schnorr e Thiago Ranniery, por sua vez, destacam em Educação para o risco: regulando a docência em ciências na era da insegurança, como o risco, alterando e modulando currículos de ciências globalmente, opera constituindo uma instável economia política moral e subjetiva da docência na era da insegurança.

O texto Educação física escolar e filantrocapitalismo: o “impulsiona” e a privatização de uma narrativa curricular, de Renato Cavalcanti Novaes, Antonio Jorge Gonçalves Soares, Theresa Adrião e Silvio de Cassio Costa Telles, problematiza a rede de influências na implementação de programas de currículo, em especial, por meio do programa 
Impulsiona, na Educação Física escolar. Desnaturaliza a narrativa de uma Educação Física atravessada por um ideal performático e que assume contornos esportivizantes, acríticos, tecnocráticos e neo-higiênicos a serviço da formação de capital humano para o mercado, cujo discurso marcado por uma racionalidade neoliberal pode acarretar em um esvaziamento curricular dessa disciplina.

Ana Paula Pereira Marques de Carvalho e Nataly da Costa Afonso destacam processos de Governança em rede: sentidos que se deslocam no movimento da formação continuada de professores alfabetizadores. Abordam o Projeto Trilhas, do Instituto Natura, para problematizar as tentativas de regulação e fixação de sentidos para a prática docente nesse movimento formativo.

O texto Criações cotidianas para além dos dispositivos de regulação da docência nas políticas de currículo na atualidade, de Andreia Teixeira Ramos, Renata Rocha de Oliveira e Elaine Sotero, destaca outros modos de criações cotidianas para além dos dispositivos de regulação da docência, presentes nas políticas de currículo na atualidade. Apresenta alguns momentos de lutas e resistências históricas com base na educação das relações étnico-raciais, indicando que é preciso e possível caminhar além dos dispositivos de regulação, objetivando se desviar das agendas impostas e propor outros movimentos criadores de resistências.

Autonomia e regulação no processo de (re)construção do currículo da educação infantil é tema do texto de Kênia Kristina Furtado, Alba Regina Battisti de Souza e Lourival José Martins Filho, sobre o processo de construção e reconstrução do currículo por docentes que atuam na Educação Infantil de uma rede municipal de ensino, considerando os movimentos entre a autonomia e a regulação. Destaca que, apesar da sobrecarrega e da culpabilização de professores e professoras, em meio à intensificação do trabalho docente, constrangendo sua autonomia, eles encontraram espaços de autonomia e, por meio desses, persistem e resistem em direção a um trabalho sensível e autoral.

Ao pé da palavra, céu acima: entre-lugar de uma docência-menos, de Cristiano Bedin da Costa e Marcos da Rocha Oliveira discute o currículo a partir de seu deslocamento e de sua transformação na cena dramática da aula. Por meio da imagem de uma razão antropofágica, a experiência de formação docente é vinculada a procedimentos de autoatualização via assimilação crítica da alteridade por intermédio da palavra. Defende a aula como entre-lugar de um canto ex-cêntrico de apropriação e transcriação: ensino e aprendizagem amalgamados a um princípio de desejo, resistência e tradição de ruptura.

O texto Disputas curriculares em torno da formação inicial e continuada no Brasil: anunciações políticas das entidades científicas, de Ana Cláudia da Silva Rodrigues, Ângela Cristina Alves Albino e Rafael Ferreira de Souza Honorato, apresenta um recorte histórico de manifestos veiculados pelas entidades científicas acerca da produção das políticas curriculares de formação docente, analisando, em especial, o movimento que antecede a Resolução 02/2019. Aborda algumas dimensões da formação em meio à crise política, sanitária e econômica e põe em evidência o posicionamento político das entidades em relação aos processos de formulação das resoluções de formação bem como, o que rejeitam como modelo formativo. 
Alexandra Garcia e Helena Amaral da Fontoura em As ideias não morrem: movimentos nas políticas curriculares e na formação docente, discutem as produções de resistências como movimentos que expressam a presença de ideias e de práticas que fogem às tentativas de controle da docência e às lógicas de centralização curricular. Destacam que as resistências se produzem para além do enfrentamento, trazendo transformações e alimentando outros caminhos com os currículos e com a formação docente que se deslocam de uma agenda oficial.

O artigo Mais regulação do professor e menos “qualidade da educação”: os deslizamentos de sentidos no campo da alfabetização, de Bárbara Rocha Souza e Veronica Borges, problematiza as significações que são disputadas nas produções científicas acadêmicas do campo da alfabetização produzidas entre os anos 2000-2019, identificando diferentes sentidos que são projetados em nome de uma melhor forma de alfabetizar. Aponta que o anseio pela ampliação do alcance da alfabetização tem sido articulado sob o manto da instrumentalidade e da padronização, funcionando mais como um dispositivo de regulação do professor e menos como qualidade da educação.

Por fim, o artigo Políticas curriculares em Portugal na segunda década do século XXI: entre lógicas de regulação compósitas e deslocamentos da ação educativa para o coletivo da escola, de autoria de Preciosa Fernandes e Paulo Marinho, focaliza a centralidade do professor e os eixos de autonomia, flexibilidade curricular e inclusão nas políticas curriculares de Portugal, problematizando a sua relação com possíveis lógicas de regulação dos professores. Os autores concluem que os discursos mais direcionados para a escola, denunciam um deslocamento do ônus da responsabilidade da decisão curricular do individual (professor) para o coletivo (escola) evidenciando, ao mesmo tempo, uma lógica de regulação híbrida/compósita do trabalho dos professores, assente em ordens centralizadas e simultaneamente localizadas.

A coletânea de artigos que reunimos neste Dossiê temático da ABdC, fruto da produção fecunda do campo do currículo, nos convida ao debate de temáticas cruciais para a políticas de currículo e docência que estamos a disputar. Desejamos aos leitores produtivas leituras.

\section{Referências}

BIESTA, Gert. Reconquistando o coração democrático da educação. Educação Unisinos - v.25, 2021, p.17.

LACLAU, Ernesto; MOUFFE, Chantal. Hegemonia e Estratégia Socialista: por uma política democrática radical. Tradução de Joanildo Burity, Josias de Paula Jr. e Aécio Amaral. São Paulo: Intermeios, 2015.

LOPES, Alice C.; OLIVEIRA, Marcia B. Redes de pesquisa e articulações discursivas nas políticas de currículo. In: Políticas de currículo: pesquisas e articulações discursivas. (Organizadoras/coordenadoras). - Curitiba: CRV. 2017 p.11-29.

ORGANIZAÇÃO DOS ESTADOS IBERO-AMERICANOS. OEI. Miradas sobre la Educación en IberoAmérica: Desarrollo profesional docente y mejora de la educación. Madrid, 2013. Disponível em: www.oei.es/publicaciones/InformeMiradas2013.pdf - Acesso em 14 de fevereiro de 2018. 2013.

ORGANIZAÇÃO DOS ESTADOS IBERO-AMERICANOS. OEI. Miradas sobre Educação na Ibero- 
América 2020: Competências para o Século XXI na Ibero-América. Madri, 2020. Disponível em: https://oei.int/pt/publicacoes/informe-miradas-2020-2. Acesso em: 25 de novembro de 2020.

\section{Correspondência}

Rosanne Evangelista Dias: Doutora em Educação pela UERJ. Professora Adjunta da Faculdade de Educação e do Programa de Pós-Graduação em Educação da Universidade do Estado do Rio de Janeiro - UERJ. Líder do Grupo de Pesquisa Políticas de Currículo e Docência com pesquisas financiadas pelo CNPq, Faperj, Capes, UERJ. Procientista do Estado e Jovem Cientista do Nosso Estado - FAPERJ.

E-mail: rosanne_dias@uol.com.br

Marcia Betania de Oliveira: Doutora em Educação pelo Programa de Pós- Graduação em Educação da Universidade do Estado do Rio de Janeiro (PROPED/UERJ). Professora Adjunta da Universidade do Estado do Rio Grande do Norte (UERN), lotada no Departamento de Educação da Faculdade de Educação (DE/FE). Credenciada no Programa de Pós-Graduação em Educação da Faculdade de Educação (POSEDUC/FE/UERN).

E-mail: marciabetaniauern@gmail.com

Texto publicado em Currículo sem Fronteiras com autorização dos autores. 